\title{
A Cross-Examination of the Perspectives on Why Natural Resource Abundant Economies Tend to Grow Slowly
}

\author{
Daniel Wandera Clief Naku \\ Department of Geography, St John's University of Tanzania - East Africa \\ P.O. Box 47 Dodoma- Tanzania
}

\begin{abstract}
It does appear to be a straightforward thinking that economies with abundant natural resources stand a better chance of growing faster than those with relatively little or no natural resources. In fact, this perception is strongly upheld by theories such as the factor proportions theory which tend to stress that if an economy has abundant resources; then it is better positioned to produce and export in large quantities those produces that use the available relatively abundant resources. However, over the years, researchers and scholars have revealed through their research and scholarly works that it is possible for an economy to have abundant resources and yet grow very slowly. On account of such preposition, a number of perspectives have been put forward attempting to explain why natural resource abundant economies tend to grow slowly. Considering that there are a number of several competing perspectives to explain the existence of this phenomenon, it is very difficult to put a finger on a single perspective as the perfect explanation for the existence of the phenomenon. In light of this situation, this paper attempts to cross-examine the various prevailing perspectives and draw conclusions on what possibly could stand out from each perspective as credible explanation for the slow growth of natural resource abundant economies.
\end{abstract}

Keywords: Economies, Natural Resources, Abundant Resources, Growth, Development

DOI: $10.7176 / \mathrm{JESD} / 10-14-13$

Publication date:July $31^{\text {st }} 2020$

\section{Introduction}

This paper attempts to cross - examine the various competing perspectives seeking to explain why natural resource abundant economies tend to grow slowly. In so doing the paper begins by positing that despite of the various perspectives that have been put forward by researchers and scholars to explain the existence of this phenomenon, it is very difficult to single out a particular perspective as the perfect explanation for the existence of the phenomenon.

Indeed, this paper notes that a number of researchers and scholars have and continue to invest their time and resources in attempting to explain the existence of this phenomenon. For instance, Murshed (2004) in his contention points out that a country with a greater endowment of natural resources relative to the rest of the World will be subject to a "winner's curse", because in the long will be worse than that of countries that have relatively lower resource endowment. This situation is attributed to the fact that such a country places a heavier reliance on natural resources in its production structure and as a result, run such a country's economic performance it is more likely to experience greater cyclical fluctuations in the trend of its national income.

Simple economic intuition tell us that if anything, a country that is well endowed with natural resources and its people have access to such resources should be seen to raise in its rate of growth. Unfortunately, as revealed through perspectives put forward by researchers and scholars, the growth trend in the so considered well endowed natural resource countries befits the explanation and the logic behind the view that having abundant resources could be a gate pass to economic growth and prosperity.

On the other hand, while there has been a lot of talk concerning the issue of resource abundance and the poor performance of countries endowed with such resources, this paper notes that amidst such talks, there is no consensus on the measurement of resource abundance as pointed out by Auty, (1998). In the long run as cited by Auty, (1998) in Sachs and Warner (1995b), some measures have been based on single indicators such as export dependence, per capita land area as stressed by Wood and Berge (1994) and labour force share by Gylfasan et al (1997). In addition as cited Auty (1998) in Syrquin and Chenery 1989, other measures consist of dual indices such as export orientation and population size.

Nevertheless, despite of the noted differences in measurements for resource abundance, the simple economic intuition that when a country has abundant resources stands better chances of experiencing economic growth cannot be watered down. As a result, the question on why natural resource abundant economies tend to grow slowly has not been ignored by researchers and scholars who have continued to state various perspectives that attempt to explain the existence of the phenomenon.

Hence, in the interest of this paper, a cross examination of the various prevailing perspectives that attempt to explain the existence of the phenomenon was found necessary so as to draw conclusions on what possibly could best explain the slow growth of natural resource abundant economies. 


\section{Methodology}

As a cross- examination research, a critical analytical approach in which perspectives on why natural resources abundant economies tend to grow slowly as revealed in literature was employed. This involved an extended literature review of the various perspectives and then a critical cross examination of the perspectives so as to draw conclusions on the findings.

\section{Perspectives on Why Resource Abundant Economies tend to Grow Slowly}

It is un-doubtable that there are a number of perspectives that have been put forward to explain the phenomenon concerning the slow growth of economies with abundant resources. However, in the context of this paper, a cross examination is limited to only four widely documented perspectives as explained below.

\subsection{The Dutch Disease Perspective}

As pointed out by Chen, (2019), Dutch disease is an economic term for the negative consequences that can arise from a spike in the value of a nation's currency. It is primarily associated with the new discovery or exploitation of a valuable natural resource and the unexpected repercussions that such a discovery can have on the overall economy of a nation. It is equally looked at as a paradox which occurs when good news, such as the discovery of large oil reserves, harms the country's broader economy which may begin with a large influx of foreign cash to exploit a newly found resource leading to a rise in currency value and thus a drop in exports and loss of jobs to other countries.

In the context of the Dutch disease perspective, when a country is said to have abundant resources, the discovery or exploitation of those natural resources is most like to cause unexpected repercussions to that country. It is as result of such repercussions that the economic growth of such a country may in one way or another be affected, leading to slow growth of the country. For instances, Sachs and Warner (2001) have argued through their empirical research that countries rich in natural resources tend to have higher price levels, and as a result their nonnatural resource based goods are uncompetitive and cannot be exported. In the end, as noted by Murshed (2004), such countries tend to miss out on the benefits of export-led growth from many other developing countries poorly endowed with natural resources have benefited. Similarly, Gylfason (2001) has argued that nations rich in natural resources under-invest in education as a proportion of national income and as a result, they pay less attention to the accumulation of human capital, something that is crowded out by their rich endowment of natural capital.

If not controlled, the Dutch disease may exhibit two chief economic effects as noted by Chen, (2019). These effects include the reduction in price competitiveness of exports of the affected country's manufactured goods and the increase in imports which result from high local currency. In the long run, sustained prevalence of these two effects lead to unemployment since manufacturing jobs will now move to lower-cost countries while non-resourcebased industries will suffer due to the increased wealth generated by resource-based industries.

In addition, Pettinger (2017) points to the fact that Dutch disease perspective is much concerned with the problems associated with a rapid increase in the production of raw materials causing a decline in other sectors of the economy and when the raw materials run out, the economy can be in a worse position than before. According to Pettinger (2017), major negative consequences of the Dutch disease when the reliance on the abundant natural resources is not well addressed may include, current account deficit, fall in tax revenue, and fall in export goods as well as unemployment. These effects according to the authors will definitely impact the growth of such countries leading to slow growth of economies in such countries.

\subsection{The Resource Curse Perspective}

The term resource curse as pointed out by McNeish (2010) is now commonly applied to describe how countries rich in natural resources are unable to use that wealth to boost their economies and how counter-intuitively these countries had lower economic growth and development outcomes than countries without an abundance of natural resources. In fact according to the Natural Resources Governance Institute (NRGI, 2015), resource curse also referred to as the paradox of plenty refers to the failure of many resource-rich countries to benefit fully from their natural resource wealth. From the resource curse perspective, this situation is reflected in having higher rates of conflict and lower rates of economic stability and economic growth in the resource abundant economies when compared to their non-resource-rich neighbors.

In addition due to resource abundance, governments become too authoritarian since they tend to assume that they have their own revenue and for that matter they do not have to depend on citizen tax collection. This perception is highly stressed by political scientists who argue that when governments depend more on citizen taxation, such governments become more responsive to what citizens tend to point out. However when governments collect more revenues from natural resources, they tend to be less dependent on levying taxes on citizens. This tends to make such governments not to pay attention to the needs of people; they do not demonstrate transparency and accountability in their deeds before citizens leading to deterioration in social services provision to people. 
Consequently according to NRGI (2015), from the resource curse perspective associated with resource abundance in a given country, internal conflicts as different groups begin to fight for control over the resources tend to occur. This ultimately destabilizes development efforts of such countries because instead of focusing on harnessing the resource and invest in development needs of the country, a lot of time and resources will be wasted in winning the conflict. Countries such as the Democratic Republic of Congo, the Niger Delta and Iraq among others have found themselves in this situation.

Another attribute linked to resource curse perspective as pointed out by NRGI, (2015) is that because of improvement in credit worthiness, countries with abundant resources tend to also over borrow. In the long run, such countries find the revenue that would have been used to finance development in the country is used to pay loans with high interests. This type of behavior leads to debt crisis when revenue from the resources decline. On the other hand, Venables (2011); also stresses that resource politics plays out in democracy and also enables autocrats to remain in power. According to the author as cited in Caselli and Cunningham (2009), resource rents alter the leader's probability of staying in power, and hence the economic, political and military strategies that are pursued.

Brock (2015) also points out that resource rich countries are said to have a tendency of over-spending during the boom period when there is high in-flow of revenue from the resources. Studies show that such governments tend to spend more on government salaries and other luxurious things while forgetting to spend on health, education and other social services. However, Torvik (2009) cautions that although overspending of resource income is one of the explanations for the resource curse perspective, it is important to investigate if resource abundant winners have different saving behavior from losers. The author (Torvik, 2009) however does note that an obstacle in using analysis that focuses on saving behavior of both resource winners and losers is that income from non-renewable resources in national accounts is misleading classified income. As a result, it will not make sense according to Torvik (2009) to simply compare saving rates of different countries.

To illustrate this scenario, Torvik uses a hypothetical example by looking at a person who owns flat worth of $\$ 100,000$ today and later decides to sell the flat at a price of $\$ 100,000$ and then deposits the money in his bank account. According to Torvik, it is not logical to conclude that this person received an income of $\$ 100,000$ today because yesterday the same person had a flat worth of $\$ 100,000$. The only difference is that this same person today he has no flat but $\$ 100,000$ in the bank. This person is neither richer nor poor than he was yesterday.

This same logic as stressed by Torvik (2009) needs to be applied in the sale of non-renewable resources in the sense that when a country sells its non-renewable resources and puts the proceeds in the financial markets, it reduces its natural capital while increasing its financial capital. From this perspective, the wealth of the country is unchanged. As a result, in using an analysis based on savings between resource abundant winners and losers, it is important as suggested by Torvik (2009) that saving rates that take into account changes in the country's resource wealth be considered. By so doing, this will allow taking all saving rates in national accounts and subtract savings in relating to non-renewable resources to obtain actual savings referred to as resource-adjusted saving rates.

\subsection{The Political Economy Perspective}

This perspective is built on three core pillars that include issues of political conflicts, Institution malfunctioning and coordination failure. Studies show that resource rich countries tend to grow slowly on account of the existing political economy that is based on the politics of the country, functioning of institutions and coordination of development in the country.

From the political point of view, Ross (2001) finds that, countries rich in mineral resources, particularly oil, do not make the transition to democracy or at least their score on an index of democracy tends to be low. There is a repression effect in which resource rich states tend to engage in higher levels of military and internal security expenditure to suppress internal dissent. On such account, political stability lacks in such countries and as a result, most if not all generated revenue from resources will be spent on addressing security issues while leading to the lack of .modernization as economic wealth does not translate into social and cultural change.

The view by Ross (2001) is further amplified by DiJohn (2002) who stressed that disputes or grievances are likely to occur in rich resource countries over the distribution of mineral rents. According to DiJohn (2002), there are several scholars who have found distributive conflicts generally increase the risk of civil war especially if resource extraction leads to land expropriation, environmental damage and large-scale migration and displacement. Another possible factor as noted by DiJohn (2002) that may induce dispute in resource rich countries could be on the distribution of rights and assets sanctioned by the state. If there is at least a passive acceptance of the distribution of rights and rents that emanate from resource income, then dispute struggles may be low. This would however mean that the issue of political legitimacy is made central to any analysis of the impact of resource abundance on political outcomes, including patterns of conflict and violence. It is when the distribution of rights is perceived as illegitimate by significant groups within a society that conflict and violence may become more likely. Generally, several studies have found that natural resources and civil war are highly correlated which appears to support the idea that rentier states are more likely to generate violence. According to Collier and 
Hoeffler (2000), the incidence of civil war increase with the dependence of a state on natural resource exports.

Regarding the aspect of institution malfunctioning, according to Chirkova (2017), one of the most famous researchers on institutions and the Nobel Prize winner Douglas North in his keynote article on institutions gave the following definition: "Institutions are the humanly devised constraints that structure political, economic and social interaction. They consist of both informal constraints (sanctions, taboos, customs, traditions, and codes of conduct), and formal rules (constitutions, laws, and property rights)." According to North as cited by Chirkova, institutions determine the spectrum of choice of economic agents, transaction and production costs, and the profitability and practicability of one type of economic activity or another. Institutions shape the system of economic incentives and specify the direction of economic changes which could be growth, stagnation, or a downturn. Chirkova further stresses that economic institutions are, first and foremost, entities that determine property rights and that regulate the execution of contracts, interactions between economic agents, and barriers to entry while political institutions are considered to be the form of the government, limitations on the behaviour of politicians and elites, the separation of powers, and the right to vote (in a democracy). Hence, according to Chirkova, those having formal political authority tend to create economic institutions, which in turn determine the distribution of resources leading to real political authority (which could be different from formal authority). Theorists of institutions maintain that economic and political institutions influence each other if a small group holds a monopoly on political power, in which case the property rights of all the rest cannot be well protected. On the other hand, if economic institutions lead to an unequal distribution of resources, political institutions cannot be democratic.

Overall, substantial body of literature suggest that differences in the quality of institutions are at the root of the diverging growth paths of successful and less successful resource rich countries. For example Mehlum et al (2006) expressed that the quality of institutions is critical in determining whether countries benefit from their abundant resources or not and according to Gelb (2010), natural resources are only found to have a negative impact on growth performance among countries with inferior institutions.

Lastly from the political economy point of view, coordination failure is also seen as one of the possible explanations as to why resource abundant economies tend to grow slow. According to Hoof (2000), in modern terms there could be coordination problems where individuals' failure to coordinate complementary changes in their actions could lead to a state of affairs that is worse for everyone than some alternative state of affairs that is also an equilibrium. In the long run, the obstacle to achieving a better state of affairs may not be because of the available abundant resources or problems relating to technological opportunities but only coordination. This view is strongly amplified in the coordination failures theory which stresses that the underdevelopment of poor countries is simply a coordination failure. In light of the view on coordination failure, literature appears to suggest that it is very possible for a country to have abundant resources and still fail grow at a desired pace simply because of coordination failures.

\subsection{The New Explanation Perspective}

This perspective was put forward by Rodriquez and Sachs (1999) as an alternative hypothesis stating that resource rich countries are most likely to grow more slowly as a result of living beyond their means. According to the two authors, natural resource industries that rely on exhaustible factors of production cannot expand at the same rate as other industries. As a result, in a steady state, production of natural resource will tend to zero. But on the transition to that steady state, the natural resource allows an economy to afford extraordinary consumption possibilities and later the resource rich economy will adjust to its steady state from above, not below. During this transition, a country's economy will display negative rates of growth average.

In view of such situation, Rodriquez and Sachs (1999), suggest that if an economy can invest its resource windfalls in international assets which pay permanent annuities, then such a situation would not occur. In addition, the authors argue that any economy experiencing a resource boom will invest it and permanently consume the interest it earns on that asset but if an economy cannot invest its resource revenues in international capital markets for different reasons, then it will have to invest them in the home country, generating temporary consumption and production booms. However, because the booms are temporary, such economies will sooner or later have to see consumption and production decline.

On account of these revelations, Rodriquez and Sachs (1999) pointed out that there is an association between lower growth rates and higher levels of income. In their view, resource abundant economies grow more slowly precisely because they have unsustainably high level income. This situation is attributed to traditional stories; political or economic distortions that tend to harm the growth rate and ultimately drive resource rich country's income below what it would have been in the absence of natural resources.

\section{Cross- examination of the Perspectives}

While the cross-examination approach may be employed to meet various goals, to a large extent, the approach is used to test the credibility and reliability of what has been said or being said. In the context of this paper, cross 
examination was employed to try and weigh in on what stands out to be of credibility from the various perspectives put forward by researchers and scholars in an effort to explain why natural resource abundant economies tend to grow slowly. Precisely four perspectives that include the Dutch disease, resource curse, political economy and the new explanation perspective based on living beyond their means perspectives have been examined in this paper. The cross-examination of the four perspectives with a focus on what appears to stand out as credible explanations from each perspective on why resource abundant economies tend to grow slowly was found to be as explained below.

In the case of the Dutch disease perspective, this paper notes that an emphasis is put on the problem of over dependence on the so called abundant natural resources while forgetting the non-natural resources. Trading along such path is considered to be very risky from three dimensions.

First, fluctuation in price levels, when natural resources have been discovered or they are simply available in abundance, they tend to come with high price levels but very prone to price falls as a result of other global forces or when they reduce in their abundance. The sudden fall in prices comes with serious repercussions that in the end destabilizes the growth trend of the country as noted by researchers such as Murshed, (2004) as well as Sachs and Warner (2001).

Second, when a country is having a lot of natural resources from which it can generate its revenue, as stressed by Murshed, (2004), there are higher chances that such a country will tend to ignore the other non-natural resource based goods which may lead to missing out on export -led growth from the non-natural resource based goods. The occurrence of this risk may imply that such a country may be exposed to slow growth from two perspectives. First, in the event that the natural resources decline or no longer on high demand as before, then income earnings will be forced to decline which will consequently affect the country's growth trend.

The second perspective in which this risk will slow down the country's growth is that the foregone income from the ignored non-natural resource based goods will not come into play to support the development of the country. For instance, if the country was earning USD 100,000 from the export of produces out of its abundant natural resources but it also has the ability to earn USD 40,000 from its non- natural based goods, then if both the natural and non-natural resource goods were to be given attention, this would imply that the country will be able to recoup USD 140,000 for investment in its development efforts. However, by ignoring the non-natural resource based goods, such a country will continue missing out on the USD 40,000 which will imply that the investment capacity will be limited to a tune of USD 100,000. This situation will therefore imply that even if the country has abundant natural resources, its growth will be slowed down since it has decided to ignore income from non-natural resource based goods.

Third, unfavourable balance of trade may set as imports will exceed exports due to high local currency as pointed out by Chen, (2019). When the country's currency gains value due to the abundant natural resources traded in and out of the country, imported goods become cheap and as a result, more importation may take place creating a state of unfavourable balance of trade. The occurrence of this risk may slow down the growth of the country in the sense that it will discourage the growth of domestic export-led industries by killing domestic markets for home produced goods. At the same time, it will lead to unemployment as many domestic firms that can no longer find consumers of their goods may be forced to close or retrench.

Generally from the above explained three dimensions in line with the Dutch disease perspective, this paper stresses that any country that takes the path of over depending on the available abundant natural resources while ignoring the non-natural resource based goods stands a higher chance of either growing slowing or find its previously attained growth decline should any of the three discussed dimensions surface.

In the case of the resource curse perspective, the paper notes that while in Dutch disease perspective the focus was on using the resources at a high dependence level, in the resource curse perspective, the focus is on being unable to use the available abundant resource to boost the growth of the country's economy as pointed out by McNeish (2010). This greatly slows down the growth of a country and it is attributed to three fundamental explanations.

First, governments becoming non-responsive to citizens needs. In this situation, governments are said to see themselves as self sufficient not needing to depend on citizen taxes to run the affairs of the state. They become too authoritarian; do not demonstrate transparency and accountability to citizens leading to deterioration in social service provision to people as noted by NRGI (2015). The consequential effects of this situation is that the government only ends up doing what it feels matters to them and not what matters to the people. This may result into depriving of people essential needs such as education, health, water and other important social services. On the other hand, the government will enjoy spending heavily in non-essential areas such as security for its own interests. This total amounts to poor management and use of income from the abundant natural resources which may subject the country to slow growth.

Second, growth in internal conflicts as different groups will begin to fight for control over the resource. The paper found this as another fundamental explanation that may arise from the resource curse perspective to slow down the growth of the country. As people begin to engage in internal fighting over the natural resources, time 
and resources that would have been directed in development matters is wasted. In the long run, the window of opportunity to make the best use of the available resources is lost which may consequently slow the growth of the country despite having abundant natural resources.

Third, debt accumulation which may heavily impacts on the development efforts of the country. The paper noted from NRGI (2015), that because of improvement in credit worthiness as a result of having abundant resources, countries in this category tend to over borrow. By so doing, these countries find themselves spending much or all the income from the resources to finance the debts. Worst of all, if the income from the resources fail to cater for the accumulated debt due to various reasons, these countries risk being faced with debt crisis.

This paper therefore noted that from the resource curse perspective, the above explained three dimensions can fundamentally explain why resource abundant economies may grow slowly.

With regard to the political economy perspective, the paper notes that the slow growth of resource abundant economies may be accelerated by three dimensions. First, undermining of democratic principles and leaders wanting to stay in power as a result of the presence or discovery of natural resources pointed out by Ross (2001). This is a political aspect in which Ross argues that in most resource abundant economies, making transition to democracy is never an easy path. Such countries tend to spend much of the income from resources to reinforce their military capacity for leaders to continue holding on power and for suppressing any internal dissent. Situations of this nature are most likely to result into political instability coupled with civil wars leading to failure to capitalize on the abundant resources to bring about growth in the country.

Second, inferior institutions that are dysfunctional and cannot enable efficient use of natural resources as cited by Gelb, (2010) contribute to resource abundant economies to grow slow. These institutions as cited by Chirkova (2017), they are humanly devised constraints that structure political, economic and social interactions. They consist of both informal constraints such as taboos, sanctions etc and formal rules such as laws, property rights etc. When these institutions are inferior and cannot guide the use of resources, then any country despite of having abundant resources may not benefit from them which may result into slow growth. Third, presence of coordination problems as cited by Hoof (2000) is equally a possible explanation as to why a country may have abundant resources and still grow slowly. In light of this view, effective coordination mechanisms are needed to ensure that resources are well harvested and income from the sale of resources is utilized as expected. To this effect, by allowing coordination failure to prevail, a country runs the risk of having resources misused and income proceeds from the resources not used for intended purposes. In such a situation, a country despite of having abundant resources may experience slowed growth.

In the context of this paper, the above three dimensions from the political economy perspective could sufficiently explain why a country with abundant resources may still grow slowly.

Lastly from the new explanation perspective as put forward by Rodriquez and Sachs (1999), this paper notes that the issue of resource rich countries having unsustainably high income levels is seen as a possible explanation as to why a country may have abundant resources and still grow slowly. To substantiate this view and in line with the proponents of this perspective, this papers concurs with the explanation that when a country has abundant resources, the possibility of experiencing high incomes is equally high in the initial stages of resource harvesting. However this is only temporary because as time goes on, the high income levels may begin to decline due to various factors. For instance, decline in resources or decline in resource demand. Such situations may subject the country that was initially enjoying high incomes from the resource to experience sharp decline in its growth and consequently begin a slow growth trend.

In this regard, this paper finds that from the perspective on living beyond their means, if the abundant resources in a particular country only enable such a country to enjoy temporary high income levels, then such a country may easily experience slow growth when the so called abundant resource can no longer enable the country to enjoy benefits of high income levels.

\section{Conclusion}

From the onset, this paper sought to cross-examine various prevailing perspectives on why resource abundant economies tend to grow slowly so as to draw conclusions on what possibly could stand out from each perspective as credible explanations for the slow growth of natural resource abundant economies. Indeed based on the revelations from the cross-examination, the explanations provided by each of the perspectives stand a chance of explaining why a country with abundant resources may end up growly slowly. In fact, the position of this paper with regard to this subject matter is that having abundant natural resources may to some extent catalyze certain growth hindering factors to surface in particular resource abundant countries.

However, a noted observation from the explanations as put forward in the examined perspectives is that; much as having abundant resources could catalyze certain factors that may propel slow growth of an economy, there is more that is not directly linked to resources that could cause a country with abundant resources to grow slowly. In fact, this paper notes that from the examined perspectives, having abundant resources only becomes harmful to the growth of the country when the manner in which such resources and earned income are used is not 
appropriate. As a result, explanations relating to a country experiencing internal conflicts, civil wars, political leaders not wanting to leave office and experiencing of unsustainable high income levels among others as noted from the examined perspectives all depend on how the country is positioned to use the resources and the earned income from the resources.

For instance, from the examined perspectives, this paper finds that natural resources have nothing to do with ensuring that coordination failures do not come up so as to prevent a country from gaining out of the existing abundant natural resources. Neither are the natural resources answerable for the presence of inferior institution. Similarly natural resources cannot cause internal conflicts or offer high incomes that can only last for a temporary period if the manner in which these resources and the earned income are used is appropriate.

Based on such circumstances, this paper therefore points out that it is very difficult and may actually not make sense to completely account for the slow growth of economies on possessed abundant natural resources. On the contrary, both internal and external driven factors that make it difficult for countries to make the best use of their available abundant natural resources should be the issues of concern.

In addition, based on the findings of this paper, the only explanation that can be given as to why countries with fewer resources tend to grow faster than those with abundant resources is that such countries seem to have put in place efficient systems to effectively use what they have and by so doing, they adequately respond to any internal and external related obstacles that they see could hamper their efficient and effective use of the fewer possessed resources.

As such, this paper therefore winds up by stressing that the perspectives as to why resource abundant economies tend to grow slowly need to avert from looking at having abundant natural resources as a problem in itself. Rather, such perspectives should see having abundant natural resources as an opportunity that has not been explored by countries gifted with these resources simply because such countries have failed to put in place mechanisms that could allow them to efficiently and effectively use the resources and the earned income. These countries have allowed both internal obstacles such as corruption, greedy, inferior institutions, sell of unprocessed resources etc and externally driven obstacles such as foreign influence and acceptance of unfavorable market prices etc to override their abilities to institute mechanisms for efficiently and effectively using the resources. In the long run, this is leading to slow growth in such countries despite of having abundant resources.

\section{References}

Auty, M.R (1998): Resource Abundance and Economic Development: Improving the performance of ResourceRich Countries, UNU/WIDER, World Institute for Development Economics Research. Research Action 44

Auty, R. M. and Gelb, A. H (2001): 'Political Economy of Resource-Abundant States', in R.M. Auty (ed.), Resource Abundance and Economic Development, Oxford: Oxford University Press.

Brock, S (2015): “The Resource Curse Exorcised: Evidence from a Panel of Countries.” Journal of Development Economics

Chen, J (2019): What is the Dutch Disease? Also accessed via: www.investopedia.com/terms/d/dutch disease.asp

Chirkova, E (2017): How institutions affect development in resource-based economies, White Paper, Carnegie Moscow Centre.

Collier, P and Hoeffler, A (2000): Greed and Grievance in Civil War,Washington D.C: World Bank. Policy Research Working Paper 2355, Development Research Group, World Bank.

DiJohn, (2002): Mineral Resource Abundance and Violent Political Conflicts: A Critical Assessment of the Rentier State model, Development Research Centre. Working Paper no. 20

Gelb, A (2010): Economic diversification in resource rich countries, Center for Global Development.

Gylfason, T (2001): Natural Resources, Education and Economic Development. European Economic Review 45: 847-59.

Gylifasan, T, T.T Herbertsson and G. Zoega (1997): A Mixed Bless: Natural Resources and Economic growth: Birkbeck College Discussion Papers in Economics, London: Birkbeck College.

Hoff, K (2000): Beyond Rosentien-Rodan: The modern theory of coordination problems in development: Annual World Bank Conference on Development Economics. The International Bank for Reconstruction and Development/World Bank

McNeish, J.A (2010): Rethinking Resource Conflict: World Development Paper 2011

Mehlum, Halvor., Karl O. Moene and Ragnar Torvik, R. 2006. "Institutions and the Resource Curse", Economic Journal, 116(508), 1-20.

Murshed, S.M (2004): When does natural resource abundance lead to a resource curse? EEP Discussion Paper 04-01.International Institute for Environment and Development (IIED), London-UK

NRGI (2015): The Resource Curse: The Political and Economic Challenges of Natural Resources Wealth. Also accessed via: www.resourcegovernance.org/sites/default/files/nrgi_Resource-Curse.pdf

Pettinger, T (2017): The Dutch Disease and why it is bad. Also accessed via: www.economicshelp.org/blog/1197/oil/dutch-disease/ 
Sachs, J. D and A. Warner (2001): The Curse of Natural Resources, European Economic Review 45: 827-38.

Sachs, J.D and A. Warner (1995b): Natural Resources and Economic growth: Mimeo, Cambridge, MA: HIID

Syrquin, M and H.B. Chenery (1989): Patterns of Development 1950 to 1983: World Bank Discussion Paper 41. Washington DC: World Bank

Torvik, R (2009): Why do some resource-abundant countries succeed while others do not? Oxford University Press, University of Oxford, United Kingdom.

Venables. J. A (2011): Using Natural Resources for Development. Why has it proven so difficult? Dept of Economics \& Oxford Centre for the Analysis of Resource Rich Economies (Oxcarre) 